\title{
ANÁLISE DA VIABILIDADE DO USO DE BIOGÁS GERADO A PARTIR DE DEJETOS BOVINOS EM MICROTURBINAS PARA FINS DE GERAÇÃO, COGERAÇÃO E TRIGERAÇÃO DE ENERGIA
}

\author{
Marcio Yukio Hirano ${ }^{1}$
}

Celso Luiz da Silva ${ }^{2}$

\begin{abstract}
RESUMO
O uso de biodigestores tem se tornado uma alternativa importante para a disposição adequada dos resíduos orgânicos agropecuários, servindo de solução para alguns problemas ambientais e sanitários. Além disso, o processo de biodigestão fornece subprodutos de grande valor comercial, como o biogás e o biofertilizante. A geração de biogás a partir de resíduos agropecuários, e seu uso em sistemas de geração de energia tem despertado grande interesse no meio rural, pois possibilita suprir integralmente ou em grande parcela a demanda energética da propriedade, reduzindo os custos de produção. $O$ advento da tecnologia trouxe novas formas de conversão energética do biogás, como o uso de microturbinas específicas para serem abastecidas com o biogás oriundo da decomposição da matéria orgânica em biodigestores, pois este apresenta baixo nível de metano em sua composição, e elevado grau de impurezas, tais como gás sulfídrico, que são prejudiciais aos equipamentos e diminuem o poder calorífico do biogás. O uso de microturbinas trás outras vantagens como baixas emissões de poluentes, grande flexibilidade de combustível e baixa manutenção. Este trabalho apresenta uma análise sobre a viabilidade do uso de biogás, gerado a partir de dejetos bovinos, em microturbinas para a geração de energia elétrica. Trás também uma avaliação do potencial energético que cada animal possui em diversas situações de uso do biogás, e as formas de aproveitamento energético dos gases de escape da microturbina. Também realiza uma avaliação sobre a economia de energia elétrica que o uso do biogás agrega a propriedades.
\end{abstract}

\section{ANALYSIS OF THE FEASIBILITY OF USING BIOGAS FROM CATTLE MANURE IN MICRO TURBINES FOR PURPOSES OF}

\footnotetext{
${ }^{1}$ Aluno de Mestrado em Engenharia Mecânica, Universidade Estadual Paulista - Campus Bauru Departamento de Engenharia Mecânica. mayuhi@hotmail.com

2 Professor Doutor em Engenharia Mecânica, Universidade Estadual Paulista - Campus Bauru Departamento de Engenharia Mecânica.celsos@feb.unesp.br
} 


\title{
GENERATION, COGENERATION AND TRIGENERATION ENERGY
}

\begin{abstract}
The use of digesters has become an important alternative for the proper disposal of organic agricultural wastes, serving as a solution to some environmental and health problems. Furthermore, the process of digestion provides commercially valuable by products such as biogas and bio fertilizer. The generation of biogas from agricultural waste, and its use in power generation systems has aroused great interest in rural areas because it enables supply in whole or in large part the energy demand of ownership by reducing production costs. The advent of technology has brought new forms of energy conversion of biogas, as the use of micro turbines specifies to be fuelled with biogas derived from the decomposition of organic matter in digesters, since it has a low level of methane in its composition, and high degree of impurities such as hydrogen sulphide, which are harmful to equipment and reduce the calorific value of biogas. The use of micro turbines behind other advantages like low emissions, great fuel flexibility and low maintenance. This paper presents an analysis of the feasibility of using biogas generated from cattle manure in micro turbines to generate electricity. Behind also an assessment of the energy potential that each animal has on various uses of biogas, and forms of energy recovery from the exhaust gases of the micro turbine. Also conducts an evaluation of the energy savings that the use of biogas aggregates properties.
\end{abstract}

\section{ANÁLISIS DE LA VIABILIDAD DEL USO DE BIOGÁS A PARTIR DE ESTIÉRCOL DE GANADO EN MICRO TURBINAS PARA FINES DE GENERACIÓN, COGENERACIÓN Y TRIGENERACIÓN DE ENERGÍA}

\begin{abstract}
RESUMEN
El uso de digestores se ha convertido en una importante alternativa para la eliminación adecuada de los desechos agrícolas orgánicos, que sirve como una solución a algunos problemas ambientales y de salud. Por otra parte, el proceso de la digestión proporciona subproductos con valor comercial como el biogás y biofertilizante. La generación de biogás a partir de residuos agrícolas, y su uso en los sistemas de generación de energía ha despertado un gran interés en las zonas rurales, ya que permite la oferta en su totalidad o en gran parte de la demanda energética de la propiedad mediante la reducción de los costos de producción. El advenimiento de la tecnología ha traído nuevas formas de conversión de energía de biogás, como el uso de micro turbinas específica para ser alimentado con biogás derivados de la descomposición de materia orgánica en digestores, ya que tiene un bajo nivel de metano en su composición, y el alto grado de impurezas tales como sulfuro de hidrógeno, que son dañinas para los equipos y reducir el valor calorífico del biogás. El uso de micro turbinas detrás de otras ventajas como bajas emisiones, una gran flexibilidad de combustible y bajo mantenimiento. Este artículo presenta un análisis de la viabilidad del uso de biogás generado a partir de estiércol de ganado en micro turbinas para generar electricidad. Atrás también una evaluación del potencial energético que cada animal tiene en diversos usos del biogás, y las formas de recuperación de energía de los gases de escape de la micro turbina. También lleva a cabo una evaluación de los ahorros de energía que el uso de biogás puede agregar en las propiedades.
\end{abstract}

PALABRAS-CLAVE: Biogás, Micro turbina, Generación de Energía 


\section{Introdução}

O desenvolvimento tecnológico e o aumento da produção industrial do país têm culminado no aumento da demanda energética, sendo necessários novos investimentos para suprir essa demanda. De acordo com dados e projeções realizados em 2014, o país possui uma demanda de mais de 66 GWh de energia elétrica. De acordo com estimativas realizadas no primeiro semestre de 2014, pela AGÊNCIA NACIONAL DE ENERGIA ELÉTRICA (ANAEEL), o país ainda depende basicamente da hidroeletricidade e dos combustíveis fósseis, como petróleo, gás natural e carvão mineral, os quais representam respectivamente cerca de $64 \%$ e 19 $\%$ da matriz energética do país. Já a biomassa representa cerca de $8 \%$, e a energia eólica próxima a $2 \%$. A elevada dependência dessas fontes energéticas expõe o país a uma fragilidade, pois as fontes convencionais de energia como as hidroelétricas têm sofrido com a falta de chuvas e seus reservatórios estão se esgotando, minimizando ou mesmo tornando nula a produção de eletricidade em algumas usinas. Uma medida a médio e longo prazo seria a projeção e construção de novas usinas hidroelétricas, entretanto estes projetos vêm sofrendo inúmeros impasses devido às suas localizações (a energia produzida precisa percorrer longas distâncias para chegar aos grandes centros consumidores), e aos impactos ambientais que podem causar.

Em curto prazo, o país dispõe de termoelétricas, que são soluções imediatas para a falta de energia elétrica, entretanto o uso de combustíveis fósseis encarece a energia produzida, além de provocar diversos problemas, como: o aumento das emissões de gases poluentes, o aumento do efeito estufa, e a diminuição e o esgotamento das reservas de petróleo e gás. Nesse âmbito, o desenvolvimento tecnológico e o uso de fontes alternativas de energia se tornam promissoras, pois além de poderem suprir a demanda de energia do país, podem diversificar a matriz energética, e com isso diminuir a dependência de uma ou outra fonte de energia.

O desenvolvimento e a modernização dos meios de produção também refletiram na agropecuária, com a introdução da mecanização e automatização. Devido a isso, a criação de gado de corte e de gado leiteiro no sistema de confinamento se intensificou muito nos últimos anos. O sistema de confinamento consiste em distribuir os animais em pequenos lotes e criá-los em currais com espaço delimitado, controlando o fornecimento de alimento e água. Este sistema propicia o 
aumento produtivo do rebanho, aumentando a produção leiteira, e diminuindo o tempo de abate do animal (gado de corte). Entretanto, a utilização do sistema de confinamento, exige alguns cuidados quanto à disposição dos resíduos produzidos. $\mathrm{O}$ acumulo de fezes, urina, camas e restos de alimentos provindo da criação dos rebanhos deverão ser tratados e dispostos corretamente para que não ocorra a poluição do meio ambiente. Quando os dejetos são dispostos incorretamente, podem ocasionar a poluição do solo (fitotoxidade) e do ar (devido às emissões de gases ácidos e gases do efeito estufa), a eutrofização de lençóis freáticos e de corpos d'água (devido ao aumento da carga orgânica disponível, que pode provocar o aumento excessivo de algas, diminuindo a quantidade de oxigênio dissolvido, e provocando a morte de peixes e de outros organismos presente na água), e a proliferação de vetores como moscas e varejeiras que podem transmitir doenças aos animais e ao ser humano. De acordo com AMARAL et al. (2004), as fezes bovinas têm sido identificado como principal reservatório de Escherichia coli e de moscas domésticas.

Segundo BERNI (2011), o uso de biodigestores está totalmente ligado na correção dos problemas ambientais e sanitários do meio rural. Basicamente o biodigestor é uma câmara, no qual são depositados resíduos orgânicos, e com o auxílio de determinados grupos de bactérias anaeróbicas, diminuem o potencial poluidor dos resíduos e os riscos sanitários que podem causar. Ao final do processo, se obtém um efluente quase inerte, que deverá ser disposto em lagoas de estabilização, para que seu residual potencial poluidor possa ser neutralizado, e também eliminar possíveis agentes patógenos que tenham sobrevivido ao processo de biodigestão. Com isso, pode se obter ao longo do processo de digestão anaeróbica, o biogás e o biofertilizante, sendo este último um excelente adubo orgânico, capaz de restaurar a microbiologia do solo e consequentemente aumentar sua produtividade. $\mathrm{O}$ biogás produzido é constituído principalmente de metano $\left(\mathrm{CH}_{4}\right)$ e gás carbônico $\left(\mathrm{CO}_{2}\right)$. O metano é um combustível gasoso de alto poder calorífico, e deve ser evitado seu lançamento direto na atmosfera, pois, este intensifica o efeito do aquecimento global. Isto se deve ao seu poder de absorção da radiação solar, que é cerca de 21 vezes maior quando comparado ao gás carbônico. 
Por ter origem na decomposição anaeróbica da matéria orgânica, que é um processo que ocorre naturalmente, o biogás é considerado um biocombustível renovável. Além disso, possui seu ciclo de carbono fechado, ou seja, o carbono lançado na atmosfera, resultante do processo de combustão, é reabsorvido novamente em alguma etapa da formação do combustível. O biogás é uma mistura de gases formados durante o processo de digestão anaeróbica pelas bactérias, sendo composto majoritariamente por metano e gás carbônico $\left(\mathrm{CO}_{2}\right)$. O metano é um hidrocarboneto de cadeia simples e possui alto poder calorífico, devido a isso, 0 biogás pode ser utilizado como combustível alternativo em propriedades rurais. Podendo ser destinado nas mais diversas aplicações como o aquecimento de água e ambientes, a secagem de grãos, cozimento de alimentos, iluminação, geração de energia elétrica, entre outras. A forma mais comum de uso do biogás é a conversão em energia elétrica e térmica. A conversão para a energia elétrica conta atualmente com auxílio de diversas tecnologias disponíveis, sendo possível seu melhor aproveitamento em microturbinas específicas, podendo apresentar bons rendimentos energéticos se forem utilizados para fins de geração, cogeração e trigeração de energia. As microturbinas modernas podem operar com o biogás recolhido diretamente do biodigestor, sem a necessidade de prévio tratamento, reduzindo custos.

A energia elétrica produzida pela microturbina pode ser utilizada na própria propriedade, reduzindo os custos de produção, ou pode ser repassada às concessionárias de energia, através do Sistema de Compensação de Energia, que gera créditos a serem utilizados nas contas de energia. Para HAMILTON (2003), o uso das microturbinas é bem visto, pois são máquinas de diversas potências, compactas e leves (podendo ser instaladas em qualquer local), apresentam baixos níveis de ruídos e vibrações, são confiáveis e necessitam de pouca manutenção. Possui também grande flexibilidade no uso de combustíveis, o que possibilita seu contínuo funcionamento, em épocas de baixa ou nenhuma produção de biogás, além de possuir baixos níveis de emissões de poluentes, dispensando o uso de filtros e lavadores de gases, que elevam o custo da energia produzida.

O calor rejeitado pelos gases de escape da microturbina pode ser reaproveitado pelo uso de regeneradores ou recuperadores de calor, que transferem o calor dos gases de escape para um fluido de trabalho. Posteriormente pode ser 
utilizado em diversos processos, tais como: secagem de grãos, aquecimento de ambiente, produção de água quente ou em processos de refrigeração por absorção.

Devido a todos estes aspectos, o presente trabalho tem por objetivo verificar a viabilidade do uso do biogás provindo da decomposição de dejetos bovinos leiteiros em microturbinas para fins de geração de energia elétrica, e o aproveitamento energético dos gases de exaustão, em sistemas de aquecimento de água e de refrigeração por absorção. Bem como, avaliar o potencial de geração de energia elétrica por animal e estimar a economia energética em uma propriedade rural destinada à criação de vacas leiteiras.

\section{DESENVOLVIMENTO}

Foi realizado o levantamento de dados sobre a demanda energética em uma propriedade rural voltada à criação de gado leiteiro. Os principais pontos de consumo energético provêm principalmente dos equipamentos destinados à produção leiteira, tais como: ordenadora mecânica, bombas hidráulicas, aspersores, ventiladores, resfriadores de leite, misturadores de ração, equipamentos de iluminação, entre outros equipamentos de pequeno porte. A estimativa média da demanda energética é de aproximadamente 9.500 kWh por mês, em uma propriedade com um rebanho de 300 vacas leiteiras.

Também foi realizado o levantamento sobre a produção média diária de dejetos por animal, que são recolhidos e dispostos em biodigestores. Realizou-se um levantamento de dados e consultas em textos literários, a respeito de biodigestores comumente utilizados em propriedades rurais, e os aspectos técnicos que levaram a sua escolha, bem como, o potencial de conversão de biogás a partir de dejetos animais, e o seu poder calorífico. Os dados sobre a produção energética e o calor rejeitado pela microturbina, pôde ser obtido com auxílio de catálogos de fabricantes. E através também, de catálogos de fabricantes, puderam ser obtidos dados sobre compressores de biogás, chillers (resfriadores) de absorção e regeneradores de calor. Posteriormente foi realizada uma análise sobre o potencial energético que pode ser gerado através da combustão do biogás em microturbinas, as formas de 
reaproveitamento energético dos gases de escape, e a economia de energia elétrica que se pode obter através da microgeração.

Através de levantamentos de dados em propriedades rurais, foi obtida a produção média diária de esterco bovino fresco por animal, que ficou em cerca de 40 $\mathrm{kg}$ de esterco bovino diariamente, os quais são dispostos em biodigestores do tipo marinha ou canadense, conforme ilustrada na figura 1.

FIGURA 1 - Biodigestor modelo da Marinha

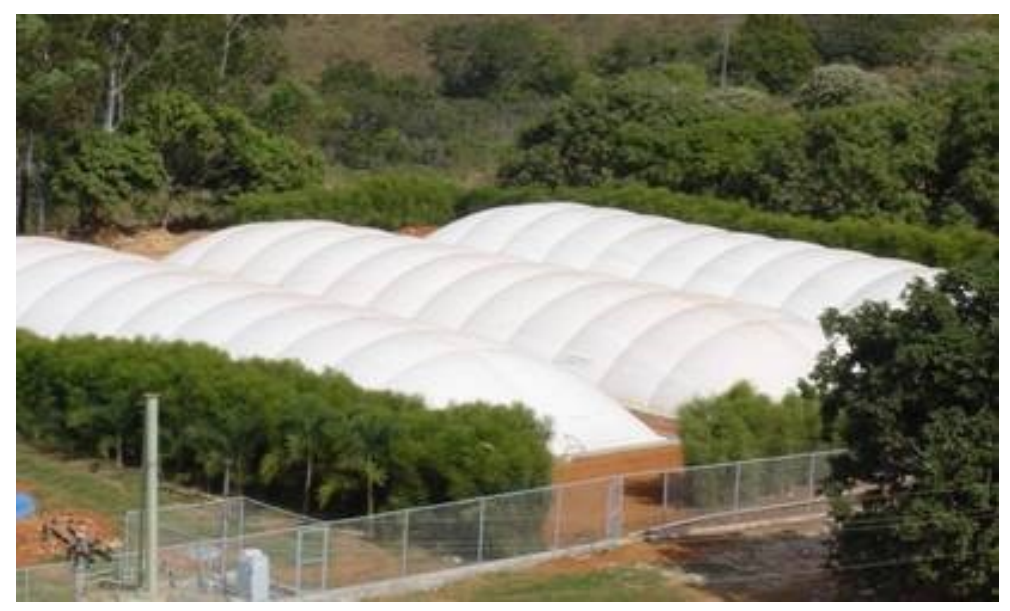

Fonte: TORRES, 2012

A escolha desse tipo de biodigestor é devida principalmente à suas características de construção, que é simples e rápida. Também favorece à sua escolha, o fato de poder ser abastecido continuamente com dejetos orgânicos, e de que suas dimensões possibilitam maior volume depositado e grande exposição solar, beneficiando a produção de biogás.

O potencial de produção do biogás varia conforme a origem e constituição orgânica dos dejetos, e pode ser calculada através da tabela 1.

TABELA 1. Potencial de produção de biogás a partir de dejetos animais

\begin{tabular}{cc}
\hline Espécie & $\mathbf{m}^{\mathbf{3}} \mathbf{\text { de biogás } / \mathbf { k g } \text { esterco }}$ \\
\hline Caprino/ovino & $0,040-0,061$ \\
Bovino de leite & $0,040-0,049$ \\
Bovino de corte & 0,040 \\
Suínos & $0,075-0,089$ \\
Frangos de corte & 0,090 \\
Poedeiras & 0,100 \\
Codornas & 0,049 \\
\hline
\end{tabular}

Fonte: OLIVER, 2008, p. 12. 
Com base nos dados da produção diária de esterco bovino, e com o auxilio dos dados sobre o potencial de conversão de biogás, ilustrada na tabela 1, pode-se obter uma produtividade de 1,6 $\mathrm{m}^{3}$ de biogás, por animal diariamente.

$O$ biogás produzido pode ser armazenado, e posteriormente utilizado nas microturbinas. A tabela 2 ilustra as formas comumente utilizadas para o armazenamento do biogás.

TABELA 2. Sistemas de armazenamento de biogás.

\begin{tabular}{ccc}
\hline Pressão [bar] & Estocagem & Material \\
\hline Baixa $(0,138$ a 0,414$)$ & Selo d'água & Aço \\
Baixa $(0,138$ a 0,414$)$ & Gás 'bag' & Plástico, vinil, lona (borracha) \\
Media $(1,05$ a 1,97$)$ & Tanques de propano e butano & Aço \\
Alta $(200)$ & Cilindros comerciais de gás & Aço \\
\hline
\end{tabular}

Fonte: KAPDI, 2004, p. 1201.

O poder calorífico que pode ser obtido através da queima do biogás depende exclusivamente da sua composição e da quantidade de água presente. A composição média do biogás é ilustrada na tabela 3 .

TABELA 3. Composição do biogás processado num biodigestor

\begin{tabular}{cc}
\hline Gases & Porcentagem (\%) \\
\hline Metano $\left(\mathrm{CH}_{4}\right)$ & 40 a 75 \\
Dióxido de carbono $\left(\mathrm{CO}_{2}\right)$ & 25 a 40 \\
Hidrogênio $\left(\mathrm{H}_{2}\right)$ & 1 a 3 \\
Nitrogênio $\left(\mathrm{N}_{2}\right)$ & 0,5 a 2,5 \\
Oxigênio $\left(\mathrm{O}_{2}\right)$ & 0,1 a 1 \\
Gás Sulfídrico $\left(\mathrm{H}_{2} \mathrm{~S}\right)$ & 0,1 a 0,5 \\
Amônia $\left(\mathrm{NH}_{3}\right)$ & 0,1 a 0,5 \\
Monóxido de carbono $(\mathrm{CO})$ & 0 a 0,1 \\
\hline
\end{tabular}

Fonte: SALOMOM; FILHO, 2007, p. 12

$O$ poder calorífico do biogás pode ser obtido com base no poder calorífico e na quantidade de gás metano presente em sua composição. Considerando que o $\mathrm{PCl}$ (poder calorífico inferior) do metano seja de $8.570 \mathrm{kcal} / \mathrm{m}^{3}\left(35.881 \mathrm{~kJ} / \mathrm{m}^{3}\right)$, o PCl do biogás sem nenhum tipo de tratamento pode variar de $3.428 \mathrm{kcal} / \mathrm{m}^{3}\left(14.352 \mathrm{~kJ} / \mathrm{m}^{3}\right)$ a $6.427 \mathrm{kcal} / \mathrm{m}^{3}\left(26.908 \mathrm{~kJ} / \mathrm{m}^{3}\right)$. Com o poder calorífico, e a produção diária de biogás, pode se obter o potencial de produção energético diário de um bovino adulto. Este pode variar de 22.963 kJ a 43.053 kJ. Para a análise de microgeração de energia, será considerado o menor potencial energético que um bovino leiteiro pode gerar, portanto, $22.963 \mathrm{~kJ} / \mathrm{dia}$. 
Foi adotada para efeitos de cálculos, a microturbina CR30, da fabricante CAPSTONE. A escolha foi motivada em função de que a mesma pode ser abastecida com biogás pobre em metano, e com elevado grau de impurezas, dispensando o uso de tratamentos específicos para a remoção de gás sulfídrico e dióxido de carbono. $A$ microturbina CR30, é ilustrada na figura 2, e suas características estão disponíveis na tabela 4.

FIGURA 2 - Microturbina Capstone CR30

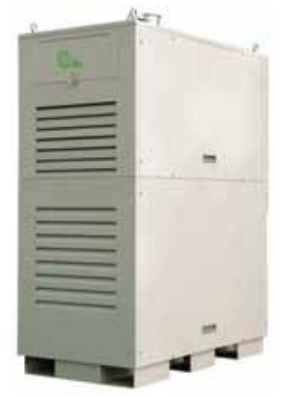

Fonte: CASPTONE, 2014

TABELA 4. Especificações técnicas da microturbina CAPSTONE CR30.

\begin{tabular}{|c|c|c|c|}
\hline \multicolumn{4}{|c|}{ Microturbina CR30 } \\
\hline \multicolumn{4}{|c|}{ Performance Elétrica } \\
\hline Potência elétrica produzida & $30 \mathrm{~kW}$ & $\begin{array}{c}\text { Máxima corrente } \\
\text { Produzida }\end{array}$ & $36 \mathrm{~A}$ \\
\hline Voltagem & $\begin{array}{c}400-480 \text { VAC } \\
\text { (trifásico - 50/60 Hz) }\end{array}$ & Eficiência elétrica & $26 \%$ \\
\hline \multicolumn{4}{|c|}{ Características do Combustível } \\
\hline $\begin{array}{l}\text { Biogás de biodigestor } \\
\text { ou aterros sanitários }\end{array}$ & $13-32,6 \mathrm{MJ} / \mathrm{m}^{3}$ & Fluxo de biogás & $457 \mathrm{MJ} / \mathrm{h}$ \\
\hline Concentração de $\mathrm{H}_{2} \mathrm{~S}$ & $<70.000$ ppm & Pressão de entrada & $414-483 \mathrm{kPa}$ \\
\hline \multicolumn{4}{|c|}{ Característica dos Gases de Exaustão } \\
\hline $\mathrm{NO}_{x} /$ produção energética & $\sim 0,29 \mathrm{~kg} / \mathrm{MWh}$ & Emissão de $\mathrm{NO}_{\mathrm{x}}$ & $\begin{array}{c}<9 \mathrm{ppm} \\
\left(18 \mathrm{mg} / \mathrm{m}^{3}\right)\end{array}$ \\
\hline $\begin{array}{l}\text { Fluxo dos gases } \\
\text { de exaustão }\end{array}$ & $0,31 \mathrm{~kg} / \mathrm{s}$ & $\begin{array}{c}\text { Temperatura dos gases } \\
\text { de exaustão }\end{array}$ & $275^{\circ} \mathrm{C}$ \\
\hline \multicolumn{4}{|c|}{ Dimensões } \\
\hline $\begin{array}{c}\text { Largura } x \text { Profundidade } x \\
\text { Altura }\end{array}$ & $0,76 \times 1,5 \times 1,8[\mathrm{~m}]$ & Peso & $405 \mathrm{~kg}$ \\
\hline Níveis de ruído a $10 \mathrm{~m}$ & $65 \mathrm{dBA}$ & & \\
\hline
\end{tabular}

Fonte: CAPSTONE, 2014

De acordo com os dados técnicos apresentados na tabela 4 , o biogás necessita entrar na microturbina com pelo menos 4,14 bares de pressão, o que implica que o biogás deve ser comprimido e armazenado em cilindros de gás especiais. Para isto, se faz necessária o uso de compressores para elevação da 
pressão do biogás. O compressor TRE 200, da MEHRER, foi selecionado, pois satisfaz à pressão de entrada do biogás na microturbina e também possui proteção contra as impurezas presentes no biogás. As características do compressor são ilustradas na tabela 5 .

TABELA 5. Dados técnicos do compressor Mehrer TRE 200

\begin{tabular}{cc}
\hline \multicolumn{2}{c}{ Compressor TRE 200 } \\
\hline Razão de compressão & $1: 6$ \\
Máxima pressão de sucção & 16 bar \\
Máxima pressão final & $16 \mathrm{bar}$ \\
Vazão volumétrica & $14,847 \mathrm{a} 26,694 \mathrm{~m}^{3} / \mathrm{h}$ \\
Potência útil necessária & $5 \mathrm{~kW}$ \\
Faixa de rotação & $350 \mathrm{a} 700 \mathrm{r} . \mathrm{p} . \mathrm{m}$. \\
Arrefecimento & $\mathrm{sim}$ \\
Compressão de gases tóxico e inflamáveis & $\mathrm{A}$ ar \\
\hline
\end{tabular}

Fonte: MEHRER, 2014

Para aumentar a eficiência global do processo, deve ser utilizado um trocador (ou regenerador) de calor, para que haja o aproveitamento dos gases de escape da microturbina. Foi selecionado o modelo ITC 1, da CAPSTONE, que possui as características apresentadas na tabela 6.

TABELA 6. Dados Técnicos do Recuperador de Calor ITC 1

\begin{tabular}{cc}
\hline \multicolumn{2}{c}{ Recuperador de Calor ITC 1 } \\
\hline Potência da Bomba de água & $2 \mathrm{HP}(1.5 \mathrm{~kW})$ \\
Tensão de Alimentação & $3 \times 380-50 \mathrm{~Hz} / 3 \times 220-60 \mathrm{~Hz}$ \\
Temperatura dos gases de escape & 275 a $305^{\circ} \mathrm{C}$ \\
Temperatura máxima de saída de água & $95^{\circ} \mathrm{C}$ \\
Vazão de Circulação de água & $120 \mathrm{l} / \mathrm{min}$ \\
\hline
\end{tabular}

Fonte: CAPSTONE, 2014

Visando aumentar ainda mais a eficiência do processo. Fez-se o uso da trigeração de energia, ou seja, a aplicação do calor residual para a produção de frio. Para isto, foi selecionado o chiller de absorção da LS GROUP, modelo LWM-W003, que opera com água quente a baixas temperaturas. Os dados técnicos do chiller são apresentados na tabela 7 .

TABELA 7. Dados Técnicos do Chiller LWM-W003

\begin{tabular}{ccc}
\hline & \multicolumn{3}{c}{ Chiller LWM-W003 } & \\
\hline Capacidade de refrigeração & $98,47 \mathrm{~kW}$ & $84.672 \mathrm{kcal} / \mathrm{h}$ \\
Água do Chiller & Temperatura de entrada & $12^{\circ} \mathrm{C}$ \\
(Fluído de refrigeração) & Temperatura de saída & $7^{\circ} \mathrm{C}$ \\
\hline
\end{tabular}




\begin{tabular}{rcc}
\hline & Temperatura de entrada & $31^{\circ} \mathrm{C}$ \\
Água de resfriamento & Temperatura de saída & $36,5^{\circ} \mathrm{C}$ \\
& Fluxo volumétrico & $37,4 \mathrm{~m}^{3} / \mathrm{h}$ \\
Água de aquecimento & Temperatura de entrada & $95^{\circ} \mathrm{C}$ \\
(Fornecimento de calor) & Temperatura de saída & $80^{\circ} \mathrm{C}$ \\
Equipamentos elétricos & Fluxo volumétrico & $8,0 \mathrm{~m}^{3} / \mathrm{h}$ \\
(bombas hidráulicas, painel de controle etc) & Potência elétrica & $4,4 \mathrm{kVA}$ \\
& Largura & $2.020 \mathrm{~mm}$ \\
Dimensões & Comprimento & $1.344 \mathrm{~mm}$ \\
& Altura & $1.952 \mathrm{~mm}$ \\
\hline
\end{tabular}

Fonte: LS GROUP, 2014

Para a análise de geração de energia, foi calculado o tempo de operação da microturbina, com base nos valores do fluxo de energia requerida pela microturbina e o poder calorífico do biogás encontrado em biodigestores. A microturbina necessita de aproximadamente $457 \mathrm{MJ} / \mathrm{h}$ de energia provinda do biogás, para gerar cerca de 26 $\mathrm{kW}$ de energia elétrica em um ambiente a $30^{\circ} \mathrm{C}$. Com base nisso, e com o poder calorífico do biogás, pode se calcular o volume de gás necessário. Portanto, deve se fornecer aproximadamente $31,84 \mathrm{~m}^{3} / \mathrm{h}$ de biogás para a microturbina. Entretanto, devido à pressão de trabalho exigido pela microturbina, o compressor de biogás necessitará de 5,91 kW de energia para armazenar $31,84 \mathrm{~m}^{3}$ de biogás á alta pressão. Desta forma, o conjunto gerador, composto pela microturbina e o compressor de biogás, fornecerá cerca de 20,09 kWh de energia líquida.

Para fornecer este volume de biogás para a microturbina, são necessários cerca de 20 animais bovinos adultos. Ou seja, cada animal possui um potencial de geração de energia elétrica de aproximadamente 1,009 kWh por dia.

Pode-se aumentar a eficiência energética do processo, com a utilização de trocadores ou regeneradores de calor, que aproveitam o calor contido nos gases de exaustão da microturbina. Com base nisso, e utilizando-se dos dados da tabela 4 e 6 , pode ser obtido durante o processo cerca de $7,2 \mathrm{~m}^{3} / \mathrm{h}$ de água quente a $95^{\circ} \mathrm{C}$. Para a produção de água quente, através do recuperador de calor ITC1, é necessária a utilização de uma bomba hidráulica que consome 1,5 kWh de energia. Portanto, cada animal bovino possui um potencial de geração de energia de aproximadamente 0,934 $\mathrm{kWh} /$ dia, além de produzir cerca de $0,361 \mathrm{~m}^{3} /$ dia de água quente.

A água quente produzida pode ser destinada para a confecção de queijos, para as lavagens do ambiente de ordenha e abatedouros, e entre outros processos 
que se faz necessário o seu uso, ou podem ser utilizados para fins de trigeração de energia, sendo aplicados em chillers de absorção, para a produção de água gelada.

Com auxílio dos dados disponíveis na tabela 7 , pode se calcular a potência frigorífica que um chiller de absorção é capaz de produzir com a água quente provinda do recuperador térmico. Com exceção da quantidade de água quente disponível, os demais parâmetros de operação são mantidos constantes. A quantidade de água quente disponível representa cerca de $90 \%$ da quantidade requerida pelo chiller, ou seja, apenas $90 \%$ da energia térmica exigida pelo chiller são entregue. Com os dados técnicos do chiller, pode-se obter seu o coeficiente de eficácia (CDE) ou de performance (COP), e com a quantidade de calor injetado no sistema, pode se calcular a nova capacidade frigorífica do chiller. Nessas condições, o chiller de absorção entrega aproximadamente 85,92 kW de refrigeração, ou seja, 24,43 toneladas de refrigeração por dia.

Neste novo cenário, o potencial de geração de energia por animal se altera, sendo possível gerar aproximadamente de 0,713 kWh por dia, além de 4,31 kW de refrigeração diariamente.

\section{CONCLUSÃO}

A destinação de dejetos bovinos leiteiros em biodigestores para a geração de biogás, e seu posterior aproveitamento energético através de sua queima em microturbinas é altamente viável, sendo possível produzir no mínimo 30,27 kWh/mês de energia por animal. A propriedade rural analisada possui cerca de 300 vacas leiteiras, com isso, é possível produzir $9.081 \mathrm{kWh} / \mathrm{mês}$ de energia elétrica, o que representa em torno de $95 \%$ de economia na energia elétrica.

Quando comparado ao sistema de produção de energia elétrica e água quente, a economia de energia elétrica representa aproximadamente $88 \%$ do total consumido, ou seja, são gerados aproximadamente $8.406 \mathrm{kWh} / \mathrm{mês}$ de energia elétrica.

No sistema em que se visa à produção de energia elétrica e produção de frio, a economia na energia elétrica chega a $67 \%$, ou seja, é possível produzir aproximadamente $6.417 \mathrm{kWh} / \mathrm{mês}$ de energia elétrica, além do beneficio de se produzir água gelada utilizada para o resfriamento de ambientes ou mesmo, para 
reduzir um pouco da temperatura do leite extraído, para posterior armazenamento. Desta forma, a economia de energia elétrica para resfriar o leite em tanques refrigerados se torna ainda maior, pois parte do calor contido no leite após sua ordenha é transferido para a água gelada.

O tratamento do biogás, através do uso de filtros simples, constituídos de serragem e limalha de ferro, contribui para a eliminação do vapor d'água e gases ácidos, que acarreta no aumento do poder calorífico do biogás e consequentemente no aumento da energia elétrica produzida pela microturbina, possibilitando a autossuficiência energética da propriedade.

Além da economia de energia, a utilização do biogás trás benefícios à natureza, pois evita que o metano seja lançado diretamente na atmosfera, diminuindo os efeitos do aquecimento global. Pode também representar uma alternativa de renda, através da comercialização de créditos de carbono, e da venda ou uso do biofertilizante.

\section{REFERÊNCIAS}

AMARAL, Cecília Maria Costa do et. al. Biodigestão anaeróbia de dejetos de bovinos leiteiros submetidos a diferentes tempos de retenção hidráulica. Revista Ciência Rural, v.34, $n^{\circ} 6$, Nov/Dez. 2004, p.1897-1902.

ANAEEL - AGÊNCIA NACIONAL DE ENERGIA ELÉTRICA. Matriz de Energia Elétrica. disponível em: <http://www.aneel.gov.br/aplicacoes/capacidadebrasil/operacaocapacidadebrasil.asp> . Acesso em: 08 de Abril de 2014.

ANAEEL - AGÊNCIA NACIONAL DE ENERGIA ELÉTRICA. Resolução Normativa N 482 - disponível em: < http://www.aneel.gov.br/cedoc/ren2012482.pdf>. Acesso em: 1 de Julho de 2014.

BERNI, Jéssica Violin. Fermentação Anaeróbica de Dejetos Bovinos em Biodigestor Canadense: Análise de Macro e Micronutrientes de Biofertilizante. 2011, 60 f. Trabalho de Graduação Faculdade de Tecnologia de Araçatuba, Araçatuba, SP, 2011.

CAPSTONE TURBINE CORPORATION. Solutions - Resource Recovery: Biogas. Disponível em: < http://www.capstoneturbine.com/_docs/datasheets/CR30_331033F_lowres.pdf>. Acesso em: Abril de 2014.

COLDEBELLA, Anderson. Viabilidade do Uso do Biogás da Bovinocultura e Suinocultura para Geração de Energia Elétrica e irrigação em Propriedades Rurais. 2006, 74 f. Dissertação de Mestrado, Universidade Estadual do Oeste do Paraná, Cascavel, PR, 2006.

COLOMA, Elena Jiménez; PRIETO, Elisabet Gonzalez. Estudio de Viabilidad de Sistemas de Purificación y Aprovechamiento de Biogás: Capítulo 6 Microturbinas. PSE PROBIOGAS, Espanha, 2010.

ENEDIS - ENERGIA DISTRIBUÍDA. Recuperador de Calor ITC 1. Disponível em: < http://www.enedis.com.ar/documents/es/Espec_Tec_ITC1_es.pdf>. Acesso em: Abril de 2014. 
GELAIN, Eduardo Rigon. Dejetos de Bovinos de Leite no Assentamento Santa Julia - Júlio de Castilhos (RS): Produção e Possibilidade de Uso. 2011, 66 f. Monografia de Especialização, Universidade Federal de Santa Maria, Santa Maria, RS, 2011.

HAMILTON, Stephanie L. Microturbine Generator Handbook. 1. ed. Tulsa, Oklahoma, PennWell Corporation, 2003, $204 \mathrm{p}$.

KAPDI, S. S et. al. Biogas Scrubbing, Compression and Storage: Perspective and Prospectus in Indian Context. Renewable Energy, v.30, 2005 p. 1195 - 1202.

LS GROUP. disponível em: <|saircondition.com>. Acesso em: 25 de Julho de 2014.

MEHRER - disponível em: < http://www.mehrer.de/1/starteite/>. Acesso em: 28 de Julho de 2014.

NISHIMURA, Rafael. Análise De Balanço Energético De Sistema De Produção De Biogás Em Granja De Suínos: Implementação De Aplicativo Computacional. 2009, 99 f. Dissertação de Mestrado, Universidade Federal de Mato Grosso do Sul, Campo Grande, MS, 2009.

OLIVER, André de Paula Moniz et. al. Manual de Treinamento em Biodigestão. 1. ed. Salvador, BA, Instituto Winrock, 2008, 23 p.

SALOMOM, Karina Ribeiro. Avaliação Técnico-Econômica e Ambiental da Utilização do Biogás Proveniente da Biodigestão da Vinhaça em Tecnologias Para Geração de Eletricidade. 2007, 247 f. Tese de Doutorado, Universidade Federal de Itajubá - Itajubá, MG, 2007.

SALOMOM, Karina Ribeiro; FILHO, Geraldo Lucio Tiago. Séries Energias Renováveis: Biomassa. 1. ed. Itajubá, MG, Centro Nacional de Referência em Pequenas Centrais Hidrelétricas, 2007, 36 p.

TECPAR - Instituto de Tecnologia do Paraná. Manual de Biossistemas Integrados na Suinocultura Centro de Integração de Tecnologia do Paraná - CITPAR. Telus - Rede Paranaense de Projetos em Desenvolvimento Sustentável. 2002, Curitiba, PR, 140 p.

TORRES, Aline et. al. Fundamentos de Implantação de Biodigestores em Propriedades Rurais. Revista Educação Ambiental em Ação, 40., 2012. Disponível em:

<http://www.revistaea.org/artigo.php?idartigo=1248\&class=02>. Acesso em: 28 de Julho de 2014. 